\title{
PRIMARY PELVIC EXENTERATION FOR ADVANCED GYNAECOLOGICAL MALIGNANCIES
}

\author{
DRAGOȘ CONSTANTIN CUCORANU ${ }^{1}$, RALUCA NICULESCU ${ }^{2}$, MIHAI EMIL CĂPÎLNA ${ }^{3}$ \\ ${ }^{1,2,3}$ Emergency Clinical County Hospital Târgu Mureș, " "George Emil Palade” University of Medicine, Pharmacy, Science and Technology of Târgu \\ Mureș Emergency Clinical County Hospital Târgu Mureș
}

Keywords: primary pelvic exenteration, complications, survival, radical

\begin{abstract}
Introduction: Indication of primary pelvic exenteration, without previous radiotherapy, is questionable in advanced stages of gynaecological malignancies. Materials and Methods: 24 patients who underwent primary pelvic exenteration for pelvic malignancies were studied retrospectively. The indications were cervical $(n=17)$, vaginal $(n=4)$, bladder $(n=2)$ and endometrial cancer $(n=1)$. Results: According to the type of exenteration, 14 were anterior and 10 total. Relying on the resection lines in relation with levator ani muscles, 14 were supralevatorial and 10 infralevatorial, of which five involved vulvectomy. Early complications occurred in 7 patients with 1 perioperative death. Conclusions: Primary pelvic exenterantion as first line therapy for advanced gynaecological malignancies can lead to long-term survival and it can even be curative in suitable selected patients. Still, postoperative complications are frequent, which can be lethal.
\end{abstract}

\section{INTRODUCTION}

Pelvic exenteration represents a surgical challenge that involves resection of the pelvic organs, including the internal genital organs and/or rectosigmoid and/or bladder in some cases, depending on the type of exenteration. Indication of primary pelvic exenteration, without previous radiotherapy, is questionable in advanced stages of gynaecological malignancies. It is considered as a last therapeutic solution for curative purposes. In addition to the experience of the gynecologic oncologist, this complex intervention involves a multidisciplinary approach, which is composed of anesthesiologists, digestive surgeons, radiologists, urologists, medical oncologists etc. It also requires a surgical service correlated with good results in terms of morbidity and mortality of patients as low as possible, and a devoted staff for adequate psychological support and postoperative care. $(1,2,3)$

The purpose of pelvic exenteration varied from palliation to potential cure due to the improvement of the surgical technique in recent years. In an attempt to reduce the high postoperative morbidity of total pelvic exenteration, diverse modifications were made in exenteration surgery, classified in: anterior, posterior, supra-levator, infra-levator and infra-levator with vulvectomy.(4)

The psychological and medical condition of the patients is crucial in performing the pelvic exenteration. The benefits of the intervention must be analysed in comparison to anesthetic and surgical risks. Another essential step for proper postoperative recovery and psychological adaptation to the changes that occur after the pelvic exenteration is the active participation of the patient. $(1,6)$

\begin{tabular}{ccc}
\hline \multicolumn{4}{c|}{ AIM } \\
This study was designed to review primary pelvic \\
exenteration performed for advanced gynaecological
\end{tabular}

malignancies in terms of patient selection, surgical procedures and complications.

\section{MATERIALS AND METHODS}

24 patients who underwent primary pelvic exenteration for pelvic malignancies, between 2011 and 2020, were studied retrospectively. In order to fulfil the purpose and objectives of the research work, the indications and contraindications were strictly observed, with patients signing a detailed informed consent before surgery, including the possible associated surgical risks. For the survival data analysis, the follow-up investigation was obtained with a written consent.

Preoperative assessment of the depth of tumour invasion and the presence of metastases was evaluated using imaging tests (endoluminal ultrasonography, computerized tomography or magnetic resonance imaging). 17 patients were diagnosed with cervical cancer stage IVa, 2 with bladder cancer stage IIIb, 4 with vaginal cancer stage IVa and 1 patient with endometrium cancer stage IVa. Operative complications were divided into early (less than 30 days from the surgical act) and late (more than 30 days from the surgical act) complications.

The data was collected, processed and retrospectively analysed using Microsoft Excel software and GraphPad Prism 8 software.

\section{RESULTS}

Ages of the patients ranged from 38 years to 66 years, with a mean age of 52.83 years. According to the type of exenteration, 14 were anterior and 10 total. Relying on the resection lines in relation with levator ani muscles, 14 were supralevatorial and 10 infralevatorial, of which five involved vulvectomy (table no. 1).

Early complications occurred in 7 patients and late complications in two patients.

${ }^{2}$ Corresponding author: Raluca Niculescu, Str. Nucului, Nr. 5, Sâncraiul de Mureș, Mureș, România, E-mail: niculescuralu@yahoo.com, Phone: $+40746980110$

Article received on 20.03.2020 and accepted for publication on 28.05.2020 


\section{CLINICAL ASPECTS}

Table no. 1. Oncologic indication and surgical procedure
\begin{tabular}{|l|c|c|}
\hline Variable & $\begin{array}{c}\text { Study Group } \\
\text { n= } 24\end{array}$ & $\begin{array}{c}\text { Percentage } \\
(\%)\end{array}$ \\
\hline Age & $\begin{array}{c}38-66 \text { y. o., mean } \\
\text { age } 54.15 \text { y. o. }\end{array}$ & $\begin{array}{c}\text { Median age } 53.5 \\
\text { y. o. }\end{array}$ \\
\hline $\begin{array}{l}\text { Type of pelvic } \\
\text { malignancy }\end{array}$ \\
\hline Cervical \\
\hline Vaginal & 17 & 70.83 \\
\hline Endometrial & 4 & 16.66 \\
\hline Bladder & 1 & 4.16 \\
\hline Type of exenteration & 2 & 8.33 \\
\hline Total & 10 & 41.66 \\
\hline Anterior & 14 & 58.33 \\
\hline $\begin{array}{l}\text { Type of procedure in } \\
\text { respect to levator ani } \\
\text { muscle }\end{array}$ & \multicolumn{2}{|l|}{} \\
\hline Supralevatorian & 14 & 58.33 \\
\hline Infralevatorian & 5 & 20.83 \\
\hline $\begin{array}{l}\text { Infralevatorian with } \\
\text { vulvectomy }\end{array}$ & 5 & 20.83 \\
\hline
\end{tabular}

There were no intraoperative deaths, all patients being monitored postoperatively, requiring pre-, intra- or postoperative blood and plasma transfusions, parenteral nutrition, antithrombotic prophylaxis, prophylactic antibiotic treatment, and intravenous albumin. All postoperative complications were classified using Clavien-Dindo system.(5) Only one (4.16\%) grade $\mathrm{V}$ complication (death before 30th postoperative days) was recorded - a patient that suffered a pulmonary embolism which led to their death on the 16th postoperative day. Four $(16.66 \%)$ patients required surgical reintervention - grade III Dindo-Clavien. Out of the 24 patients, 5 are deceased and 19 $(79.16 \%)$ are alive, without evolutionary disease (table 2 ).

Table no. 2. Survival outcomes and postoperative complications

\begin{tabular}{|l|c|c|}
\hline Variable & $\begin{array}{c}\text { Study Group } \\
\mathrm{n}=24\end{array}$ & $\begin{array}{c}\text { Percentage } \\
(\%)\end{array}$ \\
\hline Early complications & 2 & 8.33 \\
\hline Perineal wound infection & 2 & 8.33 \\
\hline Fistula & 1 & 4.16 \\
\hline Pulmonary embolism & 1 & 4.16 \\
\hline Pyelonephritis & 1 & 4.16 \\
\hline Peritonitis & 17 & 70.83 \\
\hline No complications & 2 & 8.33 \\
\hline Late complications & 22 & 91.66 \\
\hline Urostomy stenosis & 19 & 79.16 \\
\hline No complications & 5 & 20.83 \\
\hline Survival outcomes & \multicolumn{2}{|l}{} \\
\hline Alive & 22 & \\
\hline Deceased & & \\
\hline
\end{tabular}

\section{DISCUSSIONS}

Even if there is tendency to extend the indications, we must be very careful and fully observe the contraindications imposed by the patient's pathology. Before performing the primary pelvic exenteration, each case should be discussed and analysed by a multidisciplinary team and patients should be informed about the therapeutic alternatives and the possible complications.

The main pillar supporting the success of the treatment in terms of locoregional control and long-term survival is obtaining oncologic free margins after surgery, this factor being most often associated with prognosis. $(6,7,8)$

Pre- and postoperative counselling is essential in improving the patients' quality of life as well as their recovery. Many cases involve a dramatic decrease in quality of life, due to the changes that occur following pelvic exenteration, having a strong impact on their social life, physical ability and body image (changes in sex life, definitive cutaneous stomata etc.). Patients in a lower age group, as well as those not undergoing vaginal reconstruction show more noticeable changes.(9)

Because it is a radical surgery, pelvic exenteration is associated with a significant rate of complications, cited as being between $40-50 \%$ for major complications and about $80 \%$ for minor complications. Mortality is cited as between $1-16 \%$, with various causes such as sepsis, thrombembolism and cardiopulmonary insufficiency. Despite the technological advancement of the last 50 years, due to the extensive nature of the surgery, which includes high blood loss and high operative time, complications are inevitable. Infection is one of the most common morbidities (19-86\%), the most commonly reported being urinary tract infection and wound infection. Leaks from the anastomoses and fistulas within the diverting system are also relatively common, cited as between $8-36 \%$. Urethral and intestinal obstructions occur in approximately $5-10 \%$ of patients. Many of these complications can be treated conservatively, but a significant number of cases require surgery.(9) Perioperative death occurs in less than $5 \%$ of patients, the highest risk being found in women over 65 years of age.(10)

Recent years have seen considerable advances in laparoscopic surgery. The supplanting of open surgery appears inevitable in many fields of surgery as the indications for the use of Laparoscopic surgery have become more widespread. The obtainment of advanced minimally invasive surgical skills by a large of number gynecologic oncologists, coupled with technological advancement, is the driving cause behind this revolution in surgery. Data published by various centers attest to laparoscopy being an established tool in the treatment of gynecological cancer. Among the benefits provided by minimal invasive surgery are a shorter hospitalization and lower levels of postoperative pain. $(9,11,12)$

Pelvic malignant tumours are usually treated with multimodal therapies, including radiotherapy and surgical resection. Cancer recurrence usually evolves in advanced stages. Still, previous radiotherapy with high doses makes us unable to perform a proper surgical resection, turning pelvic exenteration into a difficult task full of complications. Therefore, in some cases, the only possibility of healing can be the primary pelvic exenteration.

\section{CONCLUSIONS}

Pelvic exenteration is a laborious therapeutic method associated with significant morbidity, in which selecting appropriate patients and a complete evaluation of patients operability are essential.

Primary pelvic exenteration as first line therapy for advanced gynaecological malignancies can lead to long-term survival and can even be curative in suitable selected patients. Still, postoperative complications are frequent which can be lethal.

\section{REFERENCES}

1. Căpîlna ME, Moldovan B, Becsi J, et al. Exenteraţia pelvină - tehnici chirurgicale. 1st ed. București: Editura Didactică și Pedagogică; 2016.

2. Marnitz S, Köhler $\mathrm{C}$, Müller $\mathrm{M}$, et al. Indications for primary and secondary exenterations in patients with cervical cancer. Gynecologic Oncology. 2006;103:10231030 .

3. Laszlo Ungar L, Laszlo Palfalvi, Zoltan Novak. Primary pelvic exenteration in cervical cancer patients. Gynecologic Oncology. 2008;111:S9-S12.

4. Pathiraja P, Sandhu H, Instone M, et al. Should pelvic exenteration for symptomatic relief in gynaecology malignancies be offered?.Archives of Gynecology and 
Obstetrics. 2014;289:657-662.

5. Dindo D, Demartines N, Clavien PA. Classification of surgical complications. A new proposal with evaluation in a cohort of 6336 patients and results of a survey. Annals of Surgery. 2004;240(2):205-213

6. Höckel M, Dornhofer N. Review. Pelvic exenteration for gynaecological tumours: achievements and unanswered questions. Lancet Oncol. 2006;7:837-847.

7. Friedlander M, Grogan M. Guidelines for the treatment of recurrent and metastatic cervical cancer. Oncologist. 2002;7:342-347.

8. Jager L, Nilsson PJ, Floter Radestad A. Pelvic Exenteration for Recurrent Gynecologic Malignancy. A Study of 28 Consecutive Patients at a Single Institution. Int J Gynecol Cancer. 2013;23:755-762.

9. Diver EJ, Rauh-Hain JA, del Carmen MG. Total Pelvic Exenteration for Gynecologic Malignancies. International Journal of Surgical Oncology. 2012;1-9.

10. Berek JS, Howe C, Lagasse LD, et al. Pelvic exenteration for recurrent gynecologic malignancy: survival and morbidity analysis of the 45-year experience at UCLA. Gynecologic Oncology. 2005;99(1):153-159.

11. Boggess JF, Gehrig PA, Cantrell L, Shafer A, Ridgway M, Skinner EN, et al. A comparative study of 3 surgical methods for hysterectomy with staging for endometrial cancer: robotic assistance, laparoscopy, laparotomy. Am J Obstet Gynecol. 2008;199(4):360.e1-360.e9.

12. Veljovich DS, Paley PJ, Drescher CW, Everett EN, Shah C, Peters WA. Robotic surgery in gynecologic oncology: program initiation and outcomes after the first year with comparison with laparotomy for endometrial cancer staging. Am J Obstet Gynecol. 2008;198(6):679.e1679.e10. 